\title{
Comparison of methods for solids retention time determination and control
}

\author{
Piotr Balbierz ${ }^{1, *}$, and Marta Knap ${ }^{1}$ \\ ${ }^{1}$ Wroclaw University of Science and Technology, Faculty of Environmental Engineering, Wybrzeze \\ Wyspianskiego 27, 50-370 Wroclaw, Poland
}

\begin{abstract}
Solids retention time (SRT) is the basic and most important process parameter in design, operation and control of activated sludge (AS) systems, especially with nitrification and biological nutrient removal. However, determination of SRT at the full-scale wastewater treatment plant (WWTP) may not be straightforward and the significance of proper SRT control is often underestimated by plant operators, which may lead to severe operational problems, including complete nitrification failure. This paper presents different methods for SRT determination and control, including simple hydraulic method and phosphorous mass balance method. The comparison is based on an extended data set from a large WWTP in south-west Poland, both in stable and transient operational conditions. The results of the comparison show that during stable operational conditions, all the SRT determination methods give similar results, thus the simple hydraulic method can be applied during standard operation, even at small WWTPs, which lack laboratory facilities. Hydraulic method is based on continuous on-line flowrate measurements, therefore it gives opportunity to implement an algorithm to automatically control SRT and sludge wastage from the system.
\end{abstract}

\section{Introduction}

Solids retention time (SRT) is the basic and most important process parameter in design, operation and control of activated sludge (AS) systems, especially with nitrification and biological nutrient removal. SRT influences not only the required bioreactors volume, thus the investment costs, but also oxygen demand, thus the operational costs, as well as microbiological sludge composition, thus settling properties and achieved treatment effects. Furthermore, SRT impacts waste activated sludge (WAS) production and chemical composition, hence the potential biogas production in case of anaerobic sludge digestion [1-3].

This paper aims to presents the theoretical and practical aspect of SRT determination and control at full-scale WWTPs, as well as different methods for SRT determination, including simple hydraulic method and phosphorous mass balance method. The comparison is based on an extended data set from a large WWTP in south-west Poland, both in stable and transient operational conditions.

\footnotetext{
*Corresponding author: piotr.balbierz@pwr.edu.pl
} 


\subsection{The theoretical and practical aspects of SRT determination}

SRT $(S R T, \mathrm{~d})$ is the mean residence time of AS flocs in the system, defined as the ratio of the AS mass in the system $\left(M_{X}, \mathrm{~g}\right)$ and the daily net sludge production $(\Delta X, \mathrm{~g} / \mathrm{d})$ (total sludge load entering the system and generated in the system, less the sludge load disappearing in the system ), according to the formula:

$$
S R T=\frac{M_{X}}{\Delta X}
$$

In case of a steady-state system, the daily net sludge production is equal to the daily load of sludge discharged from the system so that the SRT can be determined in a relatively simple manner. The sludge mass in the system includes the mass of sludge accumulated in the bioreactor $\left(M_{R}, \mathrm{~g}\right)$ and the secondary settling tanks $\left(M_{S S T}, \mathrm{~g}\right)$. On the other hand, the daily sludge load discharged from the system includes the sludge load discharged with wasted activated sludge $\left(\triangle X_{W A S}, \mathrm{~g} / \mathrm{d}\right)$ and the sludge load discharged in the treated effluent $\left(\Delta X_{E}, \mathrm{~g} / \mathrm{d}\right)$. Thus Eq. 1. assumes the form:

$$
S R T=\frac{M_{R}+M_{S S T}}{\Delta X_{W A S}+\Delta X_{E}}
$$

However, full-scale plants rarely work in steady-state, due to loading variations, temperature fluctuations, and changes in process parameters, thus making the correctness of the SRT determination using the classical method questionable. Generally, it is assumed that in case of real systems operating under stable operating conditions, the SRT determined by Eq. 2. allows the correct estimation of the actual SRT, especially if the average, rather than instantaneous, values for a certain period are taken into account.

However, in case of plants far from steady state, e.g. due to significant changes in the incoming load or the WAS load, the use of the classical method can lead to serious errors, since the determined SRT is only a numerical value not reflecting the actual SRT in the system. Therefore, it cannot be the basis for predicting the performance of the system. As an example, one can imagine a steady-state system working at a 5-day SRT, where the WAS load is rapidly decreased twice - as a consequence, the classical SRT increases immediately from 5 to 10 days, which is physically impossible because the sludge cannot "age" by more than $1 \mathrm{~d} / \mathrm{d}$. In fact, the time required for the system to reach the new steady state at 10-day SRT will be several days (usually a period of 3-5 time constants, in this case SRT is the time constant).

The need to determine the actual SRT in technical systems working in conditions far from steady-state led Vaccari et al. [4] to suggest the idea of dynamic SRT $\left(S R T_{D}, \mathrm{~d}\right)$, which was developed and generalized by Takacs [5], who expressed it in the form of the following differential equation, where $F_{P}(\mathrm{~g} / \mathrm{d})$ is the daily gross sludge production:

$$
\frac{d S R T_{D}}{d t}=1-\frac{S R T_{D} \cdot F_{P}}{M_{X}}
$$

The considerations and simulations by Takacs [5] showed that the dynamic SRT determined according to Eq. 3 in steady-state simplifies to the classical equation (Eq. 2), while in transient conditions it better reflects the dynamics of the AS process and correctly determines the actual SRT, and thus allows to predict the performance of the system.

It should be noted, however, that the use of dynamic SRT in practical applications is severely limited due to difficulties in reliable determination of gross sludge production due to the lack of necessary data for real systems. For this reason, the classical SRT 
determination method is usually used at WWTPs, which is not a mistake if the underlying assumption of the steady-state system and the resulting constraints is remembered.

In case of the AS system shown in Figure 1, for which further discussion will be conducted, the SRT according to the classical method (Eq. 2) can be determined as:

$$
S R T=\frac{V_{R} \cdot X_{R}+M_{S S T}}{Q_{W A S} \cdot X_{W A S}+Q_{E} \cdot X_{E}}
$$

where $V_{R}\left(\mathrm{~m}^{3}\right)$ is the bioreactor volume, $X_{R}\left(\mathrm{~g} / \mathrm{m}^{3}\right)$ is the bioreactor sludge concentration, $Q_{W A S}\left(\mathrm{~m}^{3} / \mathrm{d}\right)$ and $X_{W A S}\left(\mathrm{~g} / \mathrm{m}^{3}\right)$ are the flowrate and concentration of WAS, $Q_{E}\left(\mathrm{~m}^{3} / \mathrm{d}\right)$ and $X_{E}$ $\left(\mathrm{g} / \mathrm{m}^{3}\right)$ are the flowrate and suspended solids concentration of treated effluent.

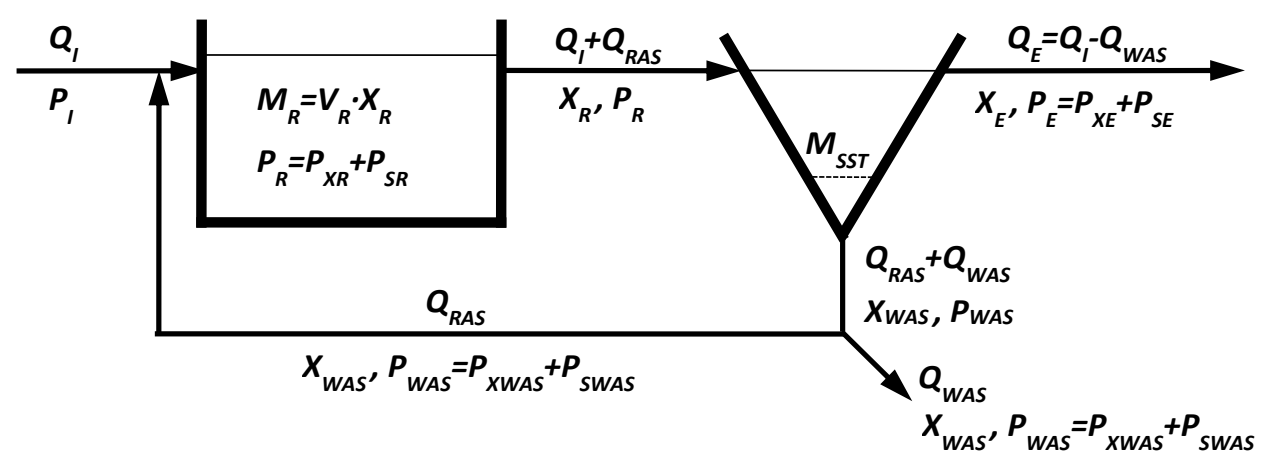

Fig. 1. Schematic diagram of AS system for the SRT considerations (description in the text).

In practical applications, simplifying assumptions are often made regarding the mass of sludge in the secondary settler and the sludge load in the effluent. The mass of sludge in settlers is often neglected, because in systems with biological nutrient removal, settlers should be operated at a low sludge layer, so the mass of sludge accumulated therein is usually relatively small, moreover, difficult to estimate without the sludge concentration profile at the depth of the settler. It is also acceptable to omit the load of sludge discharged in treated wastewater, if the suspended solids concentration is low. With these two assumptions, equation 4 . simplifies to:

$$
S R T=\frac{V_{R} \cdot X_{R}}{Q_{W A S} \cdot X_{W A S}}
$$

Therefore, to determine the SRT, it is necessary to know the values of at least four parameters. However, bioreactor volume $\left(V_{R}\right)$ is generally known and constant for a given system, and the WAS flowrate $\left(Q_{W A S}\right)$ is usually measured on-line with satisfactory resolution and accuracy. On the other hand, determination of sludge concentration usually requires laboratory analyses, results of which are delayed due to the time required to perform them, ranging from a few hours to several days, depending on whether the plant has its own laboratory. Sludge concentration in the bioreactor $\left(X_{R}\right)$ is relatively constant, so even grab samples taken once a day give reliable results, whereas WAS concentration $\left(X_{W A S}\right)$ varies significantly during the day (cf. Fig. 2), which means that successive grab samples or a daily composite sample would be needed for a meaningful result.

From the point of view of WWTP operator, the basis for SRT control, to maintain proper operating conditions in the system, is to discharge the proper load of excess sludge during the day, by applying proper WAS flowrate for the current WAS concentration.

However, due to the variability of WAS concentration, determination and control of SRT at the full-scale WWTP is not as straightforward. Moreover, the importance of proper 
SRT control is often underestimated or not fully understood by plant operators, which may lead to severe operational problems, including complete nitrification failure.

Practical problems with SRT control, urge plant operators to use other methods to determine the required excess sludge disposal. Commonly used methods are based on maintaining: a constant sludge concentration in the bioreactor, less often a constant food to microorganism ratio (due to the need for laborious and long-lasting $\mathrm{BOD}_{5}$ measurements), but also unreliable constant sludge settled volume after 30 minutes, which is strongly dependent on variable settling properties. These methods may be adequate for the operation of small organic removal systems, but do not ensure the control of the pre-set SRT, and are therefore inadequate for nitrifying and nutrient removal systems.

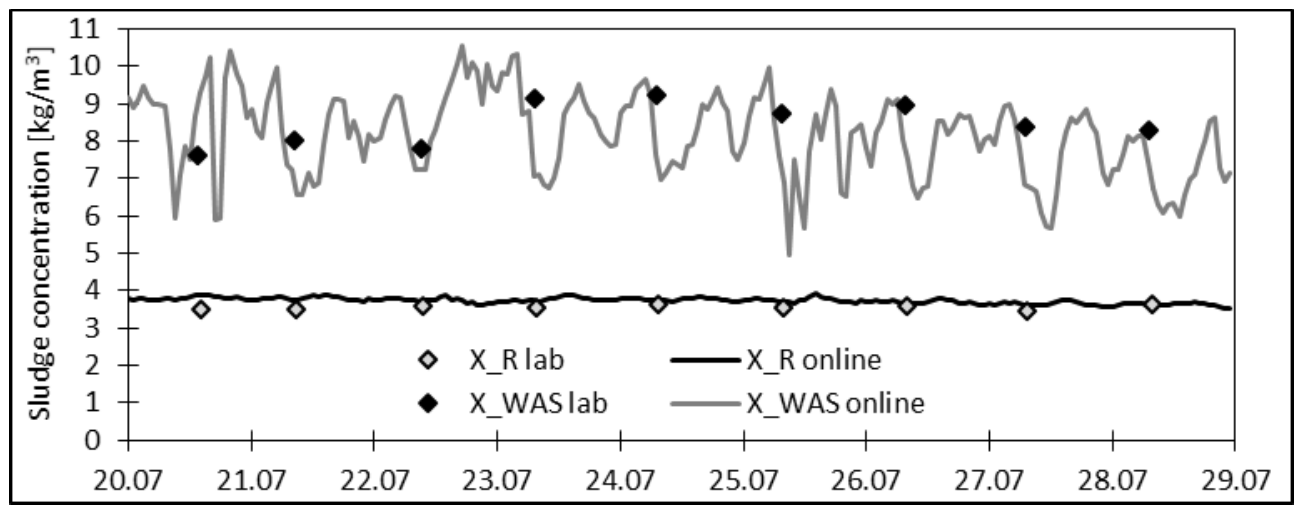

Fig. 2. Variation of sludge concentrations in bioreactor (X_R) and WAS stream (X_WAS) based on laboratory analyses (lab) and on-line measurements (online) [data from Wroclaw WWTP].

There is a very simple yet reliable method of hydraulic SRT control proposed by Garrett [6], which assumes the discharge of excess sludge directly from the bioreactor, so that the WAS concentration is equal to the bioreactor sludge concentration $\left(X_{W A S}=X_{R}\right)$, which simplifies Eq. 5 to:

$$
S R T=V_{R} / Q_{W A S}
$$

Using this method, maintaining the SRT of $n$ days requires a daily WAS discharge equal to $1 / n$ of the bioreactor volume, and does not require determination of sludge concentration. This method, however, is rarely used in practice, because its greatest advantage is also its biggest disadvantage, since the WAS stream is not thickened.

\subsection{Alternative SRT determination methods}

The importance of SRT as a process parameter of AS systems and identified problems with its determination and control, make this issue still a valid research problem. In recent years, several papers have been published that offer an original approach to this problem.

In response to problems with reliable determination of WAS concentration, Greenwood et al. [7] proposed a method for hydraulic SRT control, which is based on the sludge mass balance for bioreactors and secondary settlers. This method eliminates the need for sludge concentration analyses, because to determine the SRT it requires only the flowrates of the influent wastewater $Q_{I}\left(\mathrm{~m}^{3} / \mathrm{d}\right)$, recirculated $Q_{R A S}\left(\mathrm{~m}^{3} / \mathrm{d}\right)$ and wasted $Q_{W A S}\left(\mathrm{~m}^{3} / \mathrm{d}\right)$ AS, according to the equation:

$$
S R T_{Q}=\frac{V_{R} \cdot\left(Q_{R A S}+Q_{W A S}\right)}{Q_{W A S} \cdot\left(Q_{I}+Q_{R A S}\right)}
$$


The use of this method is particularly attractive in practical applications because it is based on on-line measurements, which allows to implement an automated algorithm to control excess sludge discharge, depending on the operating conditions of the system, to maintain the pre-set SRT. Derivation of this method, however, presupposes some simplifications as it neglects the sludge load discharged with treated effluent and assumes that there is no significant change in the mass of sludge in secondary settling tanks. Therefore, the obtained results should be periodically verified using the classical SRT determination method.

Puig et al. [8] have focused on improving the reliability of the SRT determination, particularly for the mathematical modelling of AS systems. It is recognized that for a dependable simulation study the SRT values should be known with 95\% accuracy, so it is necessary to check the quality of sludge production data $[9,10]$.

The tool that allows to verify and correct the quality and coherence of operational data is the mass balance determined for a given facility. The mass balance for the biological treatment unit can be calculated for e.g. COD, total nitrogen, total phosphorus or flow. However, only in the last two cases, if the measurements are conducted in all wastewater and sludge streams, we will be dealing with a closed balance, which will allow for its verification. Whereas for COD and nitrogen the mass balance will be open due to the component present in the gas phase - respectively $\mathrm{CO}_{2}$ or $\mathrm{N}_{2}$, which is usually not measured. Unfortunately, total phosphorus (as well as COD and total nitrogen) is usually only determined in wastewater streams, which makes it impossible to check the mass balance.

On the basis of the total phosphorus mass balance for the biological treatment unit, Puig et al. [8] proposed an alternative method to determine the SRT based on the particulate phosphorous concentration in sludge. Derivation of this method requires the assumption that there is no significant release of phosphorus from the sludge in the secondary settler. It is also necessary to know the particulate phosphorus concentration in sludge, which is calculated as a difference between the analytically determined total and dissolved phosphorus concentrations.

The first variant of this method allows to determine the SRT based on the particulate phosphorous mass in the system and the particulate phosphorus load discharged from the system according to the formula:

$$
S R T_{P E}=\frac{V_{R} \cdot P_{X R}}{Q_{W A S} \cdot P_{X W A S}+Q_{E} \cdot P_{X E}}
$$

where $P_{X R}\left(\mathrm{~g} \mathrm{P} / \mathrm{m}^{3}\right), P_{X W A S}\left(\mathrm{~g} \mathrm{P} / \mathrm{m}^{3}\right)$ and $P_{X E}\left(\mathrm{~g} \mathrm{P} / \mathrm{m}^{3}\right)$ are the particulate phosphorous concentration in the bioreactor, WAS and effluent, respectively.

The second variant allows to determine the SRT based on the particulate phosphorus mass in the system and the total phosphorus load entering the system (not necessary to determine particulate phosphorus in the WAS) according to the equation:

$$
S R T_{P I}=\frac{V_{R} \cdot P_{X R}}{Q_{I} \cdot\left(P_{I}-P_{S E}\right)}
$$

where $P_{I}\left(\mathrm{~g} \mathrm{P} / \mathrm{m}^{3}\right)$ is the total phosphorous concentration in the influent, and $P_{S E}\left(\mathrm{~g} \mathrm{P} / \mathrm{m}^{3}\right)$ is the soluble phosphorous concentration in the effluent.

It is also possible to derive a third variant, which does not require the particulate phosphorous determination at all, but because it is based on the difference between the total and soluble phosphorus concentrations in the effluent, it will be characterized by a high scatter of results: 


$$
S R T_{P N}=\frac{V_{R}}{Q_{I}} \cdot \frac{X_{R}}{X_{E}} \cdot \frac{P_{E}-P_{S E}}{P_{I}-P_{S E}}
$$

where $P_{E}\left(\mathrm{~g} \mathrm{P} / \mathrm{m}^{3}\right)$ is the total phosphorous concentration in the effluent.

Taking into account the importance of the SRT as a process parameter of AS systems and the practical difficulties encountered in reliable determination and control of SRT, the authors find it worthwhile to compare the results obtained using various methods for the operational data of the full-scale WWTP under transient and stable operating conditions.

\section{Results and discussion}

The practical verification and comparison of above-mentioned methods were carried out for operational data from Wroclaw WWTP, gathered during an 8-month period between January and August, including an intensive sampling campaign 20-28.07.

The comparison included SRT values determined by the classical method based on sludge concentrations measured in the laboratory $\left(\mathrm{SRT}_{\mathrm{XL}}\right)$ and online (SRT $\mathrm{xS}$ ), hydraulic method $\left(\mathrm{SRT}_{\mathrm{Q}}\right)$, and phosphorus mass balance based methods: based on the total phosphorus load entering the system ( $\mathrm{SRT}_{\mathrm{PI}}$ ) and the particulate phosphorus load discharged from the system (SRT $\mathrm{PE}_{\mathrm{P}}$ - only for the intensive sampling period when the phosphorus was analysed in the WAS stream).

The first half of the analysed 8-month period was characterized by very unstable and transient operational conditions. Due to problems with the operation of the sludge drying plant and limited discharge of excess sludge for over four months, in the first half of January the SRT of sludge in bioreactors of Wroclaw WWTP significantly exceeded $100 \mathrm{~d}$, and the AS concentration in bioreactor was almost $10 \mathrm{~kg} \mathrm{TSS} \mathrm{m}^{-3}$, despite only a $50 \%$ loading of WWTP, due to the renovation of the main sewer.

The nominal WAS discharge capacity was restored around mid-January, and intensive WAS discharge was begun to restore reasonable values of SRT and AS concentration as quickly as possible. However, the stable operation of the plant with effective SRT control (based on the implemented $\mathrm{SRT}_{\mathrm{Q}}$ hydraulic method) was reached only around July $1^{\text {st }}$.

The daily values of SRT determined by different methods in the 8-month period are shown in Figure 3.

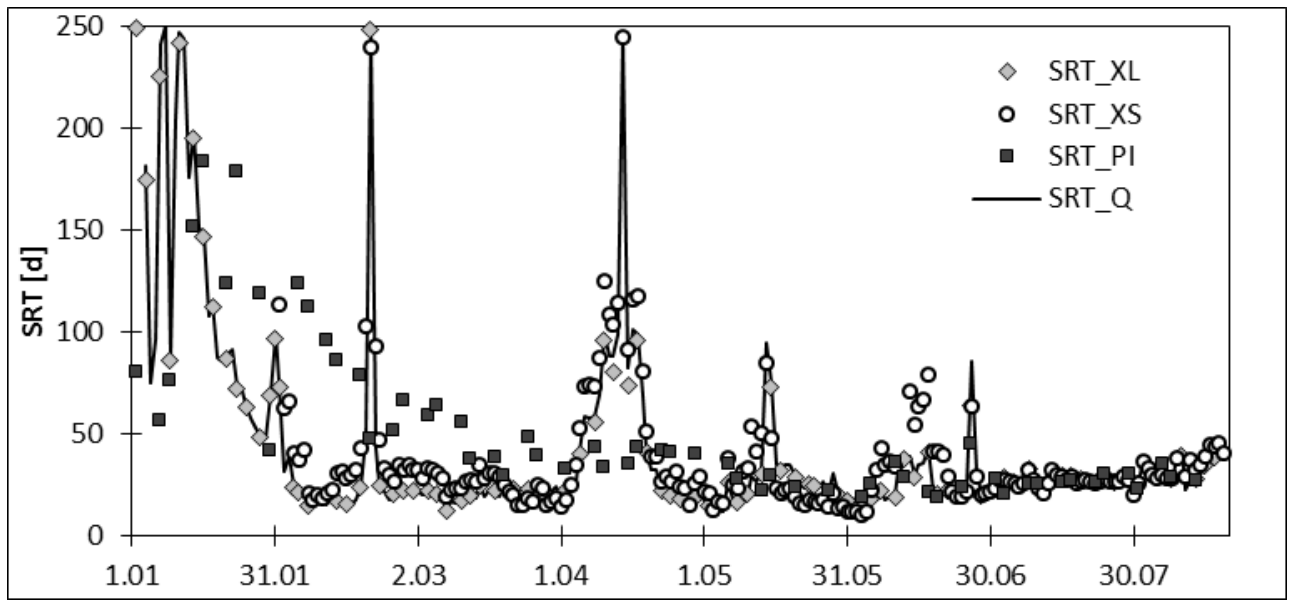

Fig. 3. Comparison of SRT determination methods in transient conditions. 
The visual evaluation of the obtained results shows that the values of $\mathrm{SRT}_{\mathrm{XL}}, \mathrm{SRT}_{\mathrm{XS}}$ and $\mathrm{SRT}_{\mathrm{Q}}$ in the whole analysed period are consistent. In contrast, values determined by the $\mathrm{SRT}_{\mathrm{PI}}$ method in the initial period are significantly higher and coincide with the results of other methods only from mid-May. The differences observed in the initial period are the result of the intensive WAS discharge after a period of operation at a very long SRT - as a result the instantaneous SRT values determined on the basis of discharged WAS load are significantly lower than the actual SRT. The SRT $_{\text {PI }}$ method, unlike the other methods, does not include the WAS load in the calculation and thus is not susceptible to rapid changes in the discharged WAS load. Thus, in such a situation the $\mathrm{SRT}_{\mathrm{PI}}$ method seems to be a better estimator of the actual value of SRT. However, it is sensitive to changes in the total phosphorus load in the influent and soluble phosphorus load in the treated effluent (changes in phosphorus removal efficiency).

A more accurate comparison of mean SRT values determined by different methods was carried out for the period 1.07.-15.08., characterized by stable operation of WWTP with effective SRT control, with special attention given to the intensive sampling campaign 20-28.07.2013 (Figure 4). Relatively short (as for the averaging of the SRT), 9-day intensive sampling period was taken into account, since only for this period laboratory measured phosphorous concentrations in the WAS stream were available.
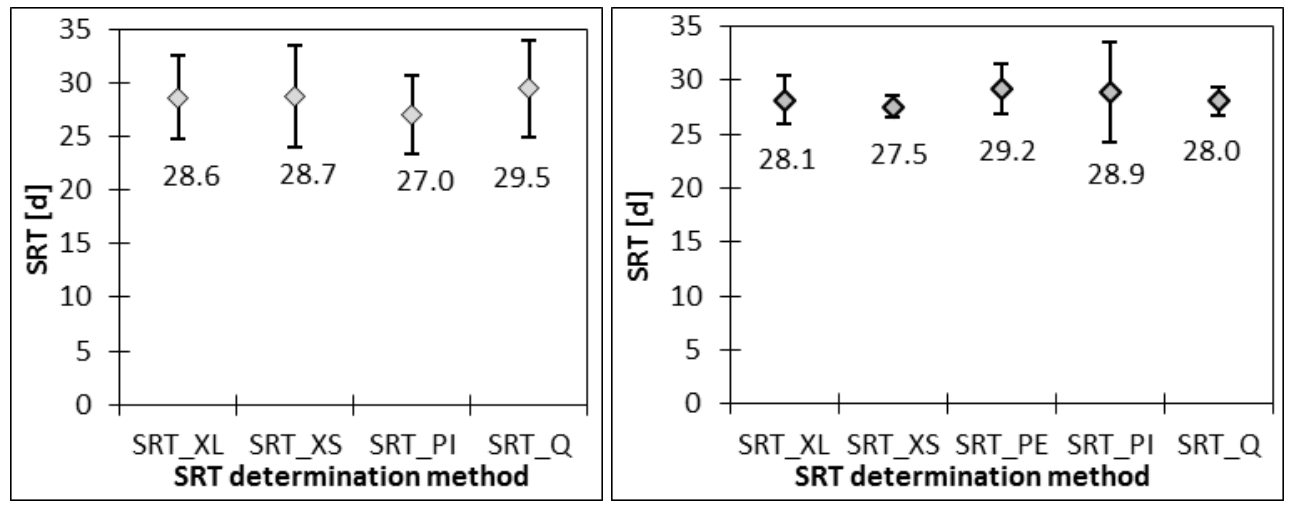

Fig. 4. Comparison of SRT determination methods during stable conditions 1.07-15.08 (left) and intensive sampling period 20-28.07 (right).

Based on the obtained results it can be stated that in the period of stable operation of WWTP, the SRT values determined by all compared methods are similar - the differences between individual methods and the classical $\mathrm{SRT}_{\mathrm{XL}}$ method (as well as the mean of all methods) generally do not exceed 1 day $(<5 \%$ of the reference value $)$ - such accuracy is completely sufficient for the operation of the WWTP.

This means that, under typical stable operating conditions, the quality of the simple hydraulic SRT control method, which is based on on-line measurements of wastewater and sludge flowrates, is comparable to the conventional SRT method. Therefore, the $\mathrm{SRT}_{\mathrm{Q}}$ method can be successfully used for the purpose of WWTP operation (with periodic verification by the classical SRT method). It is therefore possible to implement a simple and effective SRT control even in treatment plants where, due to too low frequency of sludge concentration analysis, it is not possible to control the SRT using the classical method. 


\section{Conclusions}

The SRT is the most important process parameter of AS systems; however, in unstable operational conditions typical for full-scale WWTPs, the SRT values calculated with the classical method may be unreliable and not representative. Therefore, several new SRT determination methods were proposed in the recent years to overcome those limitations.

The results of the comparison show that during stable operational conditions, all the SRT determination methods give similar results, thus the simple hydraulic method $\mathrm{SRT}_{\mathrm{Q}}$ can be applied during standard operation, even at small WWTPs, which lack laboratory facilities. Hydraulic method is based on continuous on-line flowrate measurements, therefore it gives opportunity to implement an algorithm to automatically control SRT and sludge wastage from the system.

However, during periods of rapid changes in the discharged WAS load, the SRT PI method, based on the phosphorus balance (using the total phosphorus load entering the system) provides better estimation the actual SRT value than the other methods.

\section{Acknowledgements}

The authors gratefully acknowledge co-funding from the National Centre for Research and Development (grant no. PBS2/B9/25/2014) and the Municipal Water and Sewage Company in Wroclaw.

\section{References}

1. Metcalf \& Eddy, Wastewater Engineering: Treatment and Resource Recovery (G. Tchobanoglous, F.L. Burton, H.D. Stensel, ed., McGraw-Hill Education, 2014)

2. J. Makinia, Mathematical modelling and computer simulation of activated sludge systems (London, New York, IWA Publishing, 2010)

3. G.A. Ekama, Water Sci. Technol. 61, 7 (2010)

4. D.A. Vaccari, T. Fagedes, J. Longtin, Biotechnol Bioeng. 27, 5 (1985)

5. I. Takacs, Experiments in Activated Sludge Modelling. PhD thesis, Ghent University, Ghent (2008)

6. M.T. Garrett, Sewage Ind. Wastes 30, 3 (1958)

7. S. Greenwood, C. Anderson, M. Rieth, T. Stein, Constant SRT calculated from liquid flows improves BNR activated sludge performance, Central States Water Environment Association. (2002) [online] http://www.cswea.org/papers/

8. S. Puig, M.C.M. van Loosdrecht, J. Colprim, S.C.F. Meijer, Water Res. 42, 18 (2008)

9. D. Brdjanovic, M.C.M. van Loosdrecht, P. Versteeg, C.M. Hooijmans, G.J. Alaerts, J.J. Heijnen, Water Res. 34, 3 (2000)

10. S.C.F. Meijer, M.C.M. van Loosdrecht, J.J Heijnen, Water Res. 35, 11 (2001) 